\title{
Antioxidant Effect of Vitamins in Olive Oil Emulsion
}

\author{
Francesca Cuomo* ${ }^{\circledR}$, Giuseppe Cinelli $₫$, Catalina Chirascu, Emanuele Marconi \\ and Francesco Lopez *(1)
}

Department of Agricultural, Environmental and Food Sciences (DiAAA) and CSGI, University of Molise, Via De Sanctis, I-86100 Campobasso, Italy; giuseppe.cinelli@gmail.com (G.C.); c.chirascu@studenti.unimol.it (C.C.); marconi@unimol.it (E.M.)

* Correspondence: francesca.cuomo@unimol.it (F.C.); lopez@unimol.it (F.L.)

Received: 7 May 2020; Accepted: 27 May 2020; Published: 29 May 2020

\begin{abstract}
In this study, water-in-extra virgin olive oil emulsions were enriched with vitamins. Water-in oil emulsions are heterogeneous systems able to solubilize both hydrophilic and hydrophobic compounds. Thus, hydrophilic vitamin C and lipophilic vitamin E were loaded separately or together in emulsion. A suitable emulsion composition was selected after considering different surfactant (mono and diglycerides of fatty acids, E471; sorbitan monooleate, Span 80; polyoxyethylene sorbitan monooleate, Tween 80 ) and water concentrations. The most appropriate emulsion, for the high stability, resulted the one containing concentrations of Span $801 \% w / w$ and water $1 \% w / w$. The antioxidant effect of vitamins in emulsions was studied considering the variation of the peroxide values during storage. The oxidation reaction was slowed down in emulsions containing vitamin $\mathrm{C}$, but it was quickened by the loading of vitamin $\mathrm{E}$ for its high concentration. In emulsions containing vitamin $\mathrm{E}$, indeed, the peroxide values were higher than in emulsions prepared in the absence of vitamins or in oil. The antioxidant activity generated by the co-loading of vitamin $C$ and $E$ was very effective to the point that in presence of high amounts of vitamins the peroxide values did not change in about 40 days of storage, due to the vitamin $\mathrm{E}$ regeneration by vitamin $\mathrm{C}$.
\end{abstract}

Keywords: water-in-oil emulsion; olive oil; antioxidant activity; ascorbic acid; tocopherol

\section{Introduction}

Fortified or enriched foods were introduced in the $1930 \mathrm{~s}$ and were proposed to help the increase of vitamins and minerals intake with foods. Generally, food fortification is intended with the addition of one or more essential nutrients to a food, for the specific purpose of preventing or correcting a nutrient deficiency in the population [1].

The goal of any food enrichment is increasing the nutrient intake while at the same time maintaining safe levels of intake [2]. Among nutrients, vitamins take part to several metabolic pathways in the human body and their deficiency could cause the onset of oxidative stress and diseases. Vitamin E, or $\alpha$-tocopherol, is a lipid-soluble antioxidant; in the body, it protects cellular membranes against oxidative damage [3] reducing the hydroperoxides formation [4]. Vitamin C, or ascorbic acid, is a water-soluble antioxidant; it maintains the oxidation-reduction potential and inactivates the free radical species. Food enrichment with these vitamins is not easy, since vitamin C, for instance, is degraded with thermal treatments, light, air, etc. [5] and vitamin E is easily oxidized in the air [3]. However, it has been shown that when used together these vitamins protect each other through a synergistic mechanism [6].

Among the strategies to deal with micronutrient deficiencies, the development of food matrices with peculiar structures is not an optional or secondary aspect. Emulsions consist of two or more immiscible or partially miscible liquids with one liquid dispersed in the other as droplets [7-9]. 
Such a heterogeneous system allows the co-solubilization of both hydrophilic and lipophilic molecules. A suitable emulsion formulation should retain its chemical, physical and sensorial properties over time. Nonetheless, emulsions are thermodynamically unstable, and for this reason, they face the separation of the two phases. It is well recognized that emulsion stability is ruled by the nature of the interfacial stabilizing layer, which is determined by the type and concentration of surface-active or emulsifier components and their relative affinity for the interface. Emulsifiers are amphiphilic molecules located at the interface between the dispersed and the continuous phase of an emulsion [7,10-16]. Throughout storage, the setting in of chemical reactions that occur inside the droplet, at the interfacial region or in the continuous phase may change the characteristics of the emulsion. This aspect leads to the conclusion that the type of the emulsifier plays a pivotal role in the stabilization of emulsions.

Vegetable oils are extensively used in food emulsions because of their technological and sensory properties, but they can be subject to oxidation due to unsaturated fatty acids. Among others, extra virgin olive oil use can be more appropriate as result of its lower unsaturation and its antioxidant content $[17,18]$. Generally, the rate of lipid oxidation in emulsion can be controlled by varying the features of the interfacial layer which can act as a physical wall separating pro-oxidants from the water phase and hydroperoxides in the oil phase [19]. During the oxidation of lipids in heterogeneous systems the development of oxidation products may be affected by emulsion assembly because it regulates the local concentration of both, reagents and products of the oxidation reaction [20].

The existence of pro-oxidants in the aqueous phase and lipid hydroperoxides at the emulsion droplet interface suggests that lipid oxidation in oil-in-water emulsions primarily occurs at the emulsion droplet interface emphasizing the role of the interfacial layer [21,22]. Recently, we showed that water-in-olive oil emulsions are suitable system for the enrichment practice. In this investigation, the aqueous phase was enriched with red wine polyphenols [23].

The activity of ascorbic acid has been widely investigated in bulk oils and in oil-in-water emulsions [24-28]. However, little has been reported on the effectiveness of ascorbic acid in water-in-oil emulsions. Although ascorbic acid is a powerful antioxidant, it is very sensitive to external factors and can easily lose its activity.

The synergistic effect of both the vitamins $C$ and $E$ to prevent autoxidation phenomena was previously reported $[6,29,30]$. Barcalay et al. [31] outlined that vitamin C in SDS micelle system has an important synergistic function in autoxidation of linoleic acid acting from the aqueous phase to regenerate tocopherol in the micellar phase. Gitto and co-workers showed studies with vitamin E, vitamin $C$, glutathione and desferrioxamine (desferoxamine) in rat liver homogenates highlighting the synergistic actions of melatonin with vitamin $C$ and vitamin $E$ [32]. Liu and coworkers demonstrated that the antioxidant property of a combination of lycopene, vitamin $E$, vitamin $C$ and $\beta$-carotene was substantially superior to the sum of the individual antioxidant effects [29].

The present study aimed to characterize and investigate on the fortification of water-in-extra virgin olive oil emulsion with vitamins. The antioxidant activity of the vitamins was estimated by evaluating the oil oxidation. Different emulsifiers were tested in order to find a suitable emulsion composition.

\section{Materials and Methods}

Materials. Sorbitan monooleate (Span 80), polyoxyethylene sorbitan monooleate (Tween 80), ascorbic acid (vitamin C) and $\alpha$-tocopherol (vitamin E) were from Sigma Aldrich. Lygomme, mono and diglycerides of fatty acids (E 471), was from Cargill. Extra Virgin olive oil (Olivae oleum Virginale) was purchased in a local store (see [23] for composition details). All reagents used were of analytical grade.

Preparation of water-in-oil emulsions (w/o). W/o emulsions were prepared by mixing oil with emulsifier and various amount of water. Emulsions containing ascorbic acid and/or $\alpha$-tocopherol were all prepared by mixing vitamin $\mathrm{E}$ and emulsifier in oil and ascorbic acid in the water phase. The ascorbic acid concentration was chosen according to the range of concentrations previously used [33]. The same molar quantities were used for vitamin E. Oil and water phases were then mixed through a homogenizer Ultra-Turrax (IKA, Staufen, Germany) for two minutes at 24,000 rpm. 
Stability of emulsion. Stability of w/o emulsions was estimated through turbidity spectra. Spectrophotometric measurements were carried out in the 900-400 nm range, at $25{ }^{\circ} \mathrm{C}$, with a Cary 100 Bio UV-Vis spectrophotometer from Varian using quartz cells with a path length of $1 \mathrm{~cm}$. Experiments were performed on diluted (in oil) emulsions (with ratio of 1:6). Samples were analyzed by measuring the turbidity ratio at two different wavelengths $(850 \mathrm{~nm} / 450 \mathrm{~nm})$ of the samples for two hours.

Peroxides determination. Peroxide values (PV) were determined according to the methods described by the EEC Regulation 2568/91 [34]. Data reported are the mean of three replicates.

\section{Results and Discussion}

The first step of the present investigation was centered on the choice of a suitable emulsifier and on the appropriate amount for the assembly of a suitable and stable water-in-olive oil emulsion. The hydrophilic-lipophilic balance parameter (HLB) allows choosing the emulsifiers according to the type of system to stabilize. As a rule, high values of HLB correspond to emulsifiers with hydrophilic characteristics, which are mostly used in the stabilization of oil-in-water emulsions $(\mathrm{o} / \mathrm{w})$; on the contrary, emulsifiers with low HLB values are more suitable for stabilizing w/o emulsions. Based on this consideration, three different surfactant systems were tested to stabilize a certain amount of water in extra virgin olive oil. In this study, E 471 and Span 80 were used individually or in combination with Tween 80 . The food additive E 471 (mixture of mono and diglycerides of fatty acids) is widely used as additive for baking or for the production of ice cream [35]. Being composed of a mixture of mono and diglycerides, its HLB value is not univocal and in the literature HLB values for $\mathrm{E}$ 471 range from 3 to 6 which correspond to the behavior of antifoaming, emulsifying and humectant agents [36].

Span 80 is also a food additive indicated with the abbreviation E 494 and has an HLB value of 4.3, which identifies lipophilic emulsifying agents to stabilize reverse emulsions (w/o) [37].

Tween 80 is a hydrophilic surfactant with an HLB value of 15 . It is used as an emulsifier for the preparation of direct systems $(\mathrm{o} / \mathrm{w})$. In this investigation, Tween 80 was used in a mixture with Span 80 to obtain an overall HLB value of 6.5 [38]. The composition of the w/o emulsions prepared is displayed in Table 1.

Table 1. Composition of water-in-oil emulsions (w/o) emulsion systems.

\begin{tabular}{cccccc}
\hline Sample & Oil (\%) & Water (\%) & E471 (\%) & Span80 (\%) & Tween80 (\%) \\
\hline 1 & 98.9 & 1 & 0.1 & - & - \\
2 & 98.8 & 1 & 0.2 & - & - \\
3 & 97.9 & 2 & 0.1 & - & - \\
4 & 97.8 & 2 & 0.2 & - & - \\
5 & 97.5 & 2 & 0.5 & - & - \\
6 & 98.5 & 1 & - & 0.5 & - \\
7 & 98.0 & 1 & - & 1.0 & - \\
8 & 97.75 & 1 & - & 0.75 & 0.5 \\
\hline
\end{tabular}

Analyses of the emulsion stability were performed by turbidity experiments. Figure 1 display the spectrophotometric spectra collected within $2 \mathrm{~h}$ for emulsions prepared with different types of emulsifiers. Panels A and B of Figure 1 show two distinct examples of unstable and stable systems, respectively. Figure 1A displays spectra belonging to sample 3 (Table 1), which reports marked differences among spectra within time. As shown, the variations at low wavelength were higher compared to those at higher wavelength. On the contrary by analyzing sample 7 (Table 1) a very slight variation of the spectra within time can be observed (Figure 1B). The relative size distribution of an emulsion can be estimated from the turbidity spectra at two widely separated wavelengths. The intensity of scattered light increases with decreasing the droplet diameter, thus when simultaneous 
flocculation and creaming occur particle size distribution shifts to larger particle sizes, owing to flocculation of the small particles, endangering the emulsion stability (Figure 1A).
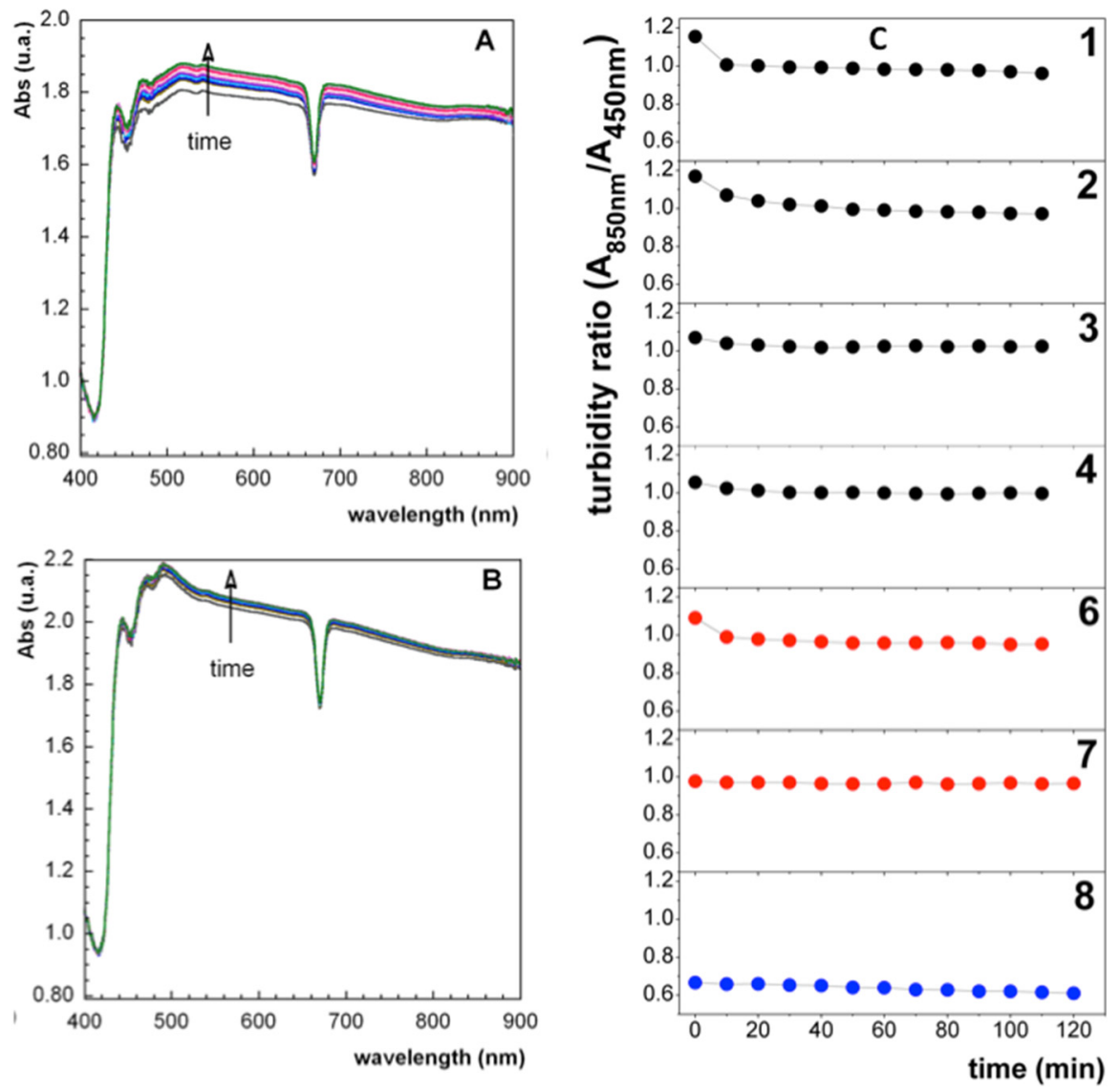

Figure 1. (A) turbidity spectra of w/o emulsions (sample 3) of Table 1; (B) turbidity spectra of sample 7 of Table $1 ;(C)$ turbidity ratio $\left(\mathrm{A}_{850 \mathrm{~nm}} / \mathrm{A}_{450 \mathrm{~nm}}\right)$ as a function of time. Panels from 1 to 4 refer to emulsion prepared with E471 as emulsifier, according to the compositions reported in Table 1. Panels 6-7 are relative to samples prepared using Span 80 at concentrations $0.5 \%$ and $1.0 \%$, respectively. Panel 8 is relative to emulsion prepared with Span 80 and Tween 80 .

The change of turbidity ratio as a function of time shows the relative emulsion breaking process more accurately compared with turbidity at single wavelength [39]. The turbidity ratio between 850 and $450 \mathrm{~nm}$ as a function of time is reported in Figure 1C for all the emulsions listed in Table 1. As can be seen from Figure 1C, the turbidity ratio remained unchanged in sample 7 only. Moreover, it is evident that sample 5 is not represented in Figure 1C since, immediately after homogenization it separated in oil and water phases. Due to its extremely high instability it was excluded from the spectrophotometric investigation.

After this phase we selected sample 7 as the suitable composition for further tests (Span 80 1\%; water $1 \%)$.

Energy for emulsion preparation was supplied through a homogenizer at high speed, which is a condition that triggers the reaction of oxidation. During storage lipid oxidation of olive oils provokes the loss of nutritional value and the formation of undesirable compounds, like lipid hydroperoxides, more polar than the starting lipids. The scheme of the three phases of the oxidation process is the following:

\section{Initiation}

$$
\mathrm{RH}+\text { initiator (oxygen, metal, etc.) } \rightarrow \mathrm{R}^{\bullet}+\mathrm{H}^{\bullet} \text { (initiator) }
$$




\section{Propagation}

$$
\begin{gathered}
\mathrm{R}^{\bullet}+\mathrm{O}_{2} \rightarrow \mathrm{ROO} \\
\mathrm{ROO}^{\bullet}+\mathrm{RH} \rightarrow \mathrm{ROOH}+\mathrm{R}^{\bullet}
\end{gathered}
$$

Termination

$$
\begin{aligned}
\mathrm{ROO}^{\bullet}+\mathrm{R}^{\bullet} & \rightarrow \mathrm{ROOR} \\
\mathrm{R}^{\bullet}+\mathrm{R}^{\bullet} & \rightarrow \mathrm{RR}
\end{aligned}
$$

$\mathrm{R}=$ lipid alkyl; species marked with $(\bullet)$ are radical molecules.

It has been previously suggested that in veiled oils or in w/o emulsions, the hydroperoxides can diffuse towards the water-oil interface thus affecting the rate of lipid oxidation [40]. To provide additional protection against oil oxidation, the emulsions have been enriched with antioxidant molecules. The aqueous phase was enriched with vitamin $C$ and the oil phase with vitamin $E$. The vitamins were added to the emulsions separately or together, at two concentrations (indicated as low and high, vide infra), vitamin $E$ was also added to the oil in absence of water (see also Scheme 1). All the combinations considered are presented in Table 2.

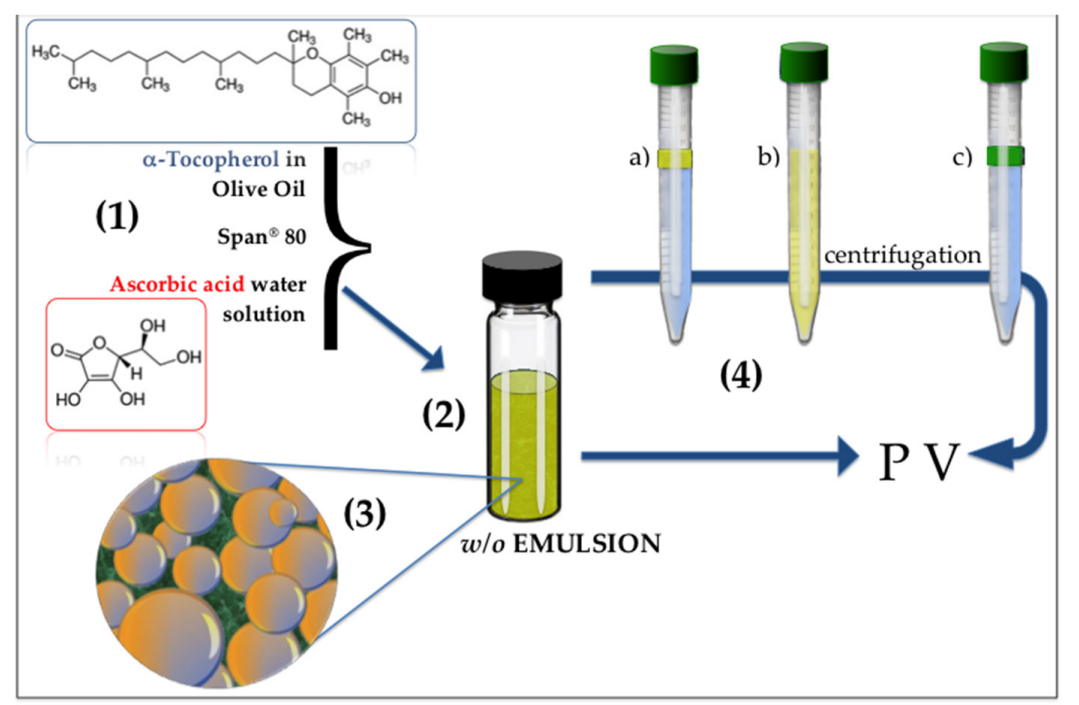

Scheme 1. Schematic representation of emulsion preparation for the peroxide values (PV) determination. (1) List of the components homogenized to form (2) the emulsion, (3) magnification of the w/o emulsion structure, (4) PV determination. For PV determination in emulsions containing vitamin $\mathrm{C}$ an aliquot was (a) diluted with water, (b) mixed (c) separated through centrifugation; the oil separated was analyzed according to the official protocol. The other samples were analyzed without separation.

The reaction of oxidation in the presence or absence of vitamins was investigated through the determination of the peroxide value (PV) over 40 days from the sample preparations. Initial PV for the extra virgin olive oil used was around $7 \mathrm{me} \mathrm{O}_{2} / \mathrm{kg}$ of oil.

In samples containing vitamin $\mathrm{C}, \mathrm{E}-\mathrm{C}(\mathrm{L}), \mathrm{E}-\mathrm{C}(\mathrm{H}), \mathrm{E}-\mathrm{C} / \mathrm{E}(\mathrm{L})$ and $\mathrm{E}-\mathrm{C} / \mathrm{E}(\mathrm{H})$ a slight modification to the $\mathrm{PV}$ measuring protocol was made because ascorbic acid was oxidized by $\mathrm{I}_{2}$ (formed from the reaction between hydroperoxides and KI) to dehydroascorbic acid and iodine [41]. As a consequence, there was no $\mathrm{I}_{2}$ to be determined through titration with thiosulfate. To prevent the reaction between vitamin $\mathrm{C}$ and $\mathrm{I}_{2}$ samples were first diluted with water and further centrifuged at $8000 \mathrm{rpm}$ for $1 \mathrm{~h}$ in order to have $1 \mathrm{~g}$ of oil sample free from water and vitamin $\mathrm{C}$ to process for the PV value determination. For sake of clarity, a schematic representation of the sample treatment is presented in Scheme 1. The scheme shows that vitamin $C$ and vitamin E were solubilized separately in the water and in the oil phases, respectively. The emulsions containing ascorbic acid were processed according to the steps illustrated 
in Scheme 1: (a) water addition to an emulsion aliquot, (b) mixing (c) oil separation after centrifugation and PV determination. The other samples were processed according to the official protocols.

Table 2. Composition of samples in the presence or absence of vitamins. Sample abbreviation: E-w/o emulsion; E-C(L)—w/o emulsion enriched with low concentration of vitamin $\mathrm{C} ; \mathrm{E}-\mathrm{C}(\mathrm{H})$ - w/o emulsion enriched with high concentration of vitamin $\mathrm{C} ; \mathrm{E}-\mathrm{E}(\mathrm{L})$-w/o emulsion enriched with low concentration of vitamin $\mathrm{E} ; \mathrm{E}-\mathrm{E}(\mathrm{H})-\mathrm{w} / \mathrm{o}$ emulsion enriched with high concentration of vitamin $\mathrm{E}$; $\mathrm{E}-\mathrm{C} / \mathrm{E}(\mathrm{L})$ - w/o emulsion enriched with low concentration of vitamin $\mathrm{C}$ and $\mathrm{E} ; \mathrm{E}-\mathrm{C} / \mathrm{E}(\mathrm{H})$ - w/o emulsion enriched with high concentration of vitamin $\mathrm{C}$ and $\mathrm{E} ; \mathrm{O}-\mathrm{E}(\mathrm{L})$ - oil enriched with low concentration of vitamin $\mathrm{E} ; \mathrm{O}-\mathrm{E}(\mathrm{H})$ - oil enriched with high concentration of vitamin $\mathrm{E} ; \mathrm{O}$-oil.

\begin{tabular}{ccccc}
\hline Sample & Span 80 (\%) & Water (\%) & Vitamin C (mol) & Vitamin E (mol) \\
\hline E & 1.0 & 1.0 & - & - \\
E-C(L) & 1.0 & 1.0 & $1.5 \times 10^{-5}$ & - \\
E-C(H) & 1.0 & 1.0 & $1.05 \times 10^{-4}$ & - \\
E-E(L) & 1.0 & 1.0 & - & $1.5 \times 10^{-5}$ \\
E-E(H) & 1.0 & 1.0 & - & $1.05 \times 10^{-4}$ \\
E-C/E(L) & 1.0 & 1.0 & $1.5 \times 10^{-5}$ & $1.5 \times 10^{-5}$ \\
E-C/E(H) & 1.0 & 1.0 & $1.05 \times 10^{-4}$ & $1.05 \times 10^{-4}$ \\
O-E(L) & - & - & - & $1.5 \times 10^{-5}$ \\
O-E(H) & - & - & - & $1.05 \times 10^{-4}$ \\
O & - & - & - & - \\
\hline
\end{tabular}

Figure 2 shows PV values over time on the w/o emulsion fortified with ascorbic acid. The Figure compares the PV evolution of E, w/o emulsion without addition of any vitamin, with E-C(L) and $\mathrm{E}-\mathrm{C}(\mathrm{H}) \mathrm{w} / \mathrm{o}$ emulsions enriched with low and high concentration of vitamin $\mathrm{C}$, respectively, and with oil $(\mathrm{O})$ in absence of water and vitamins.

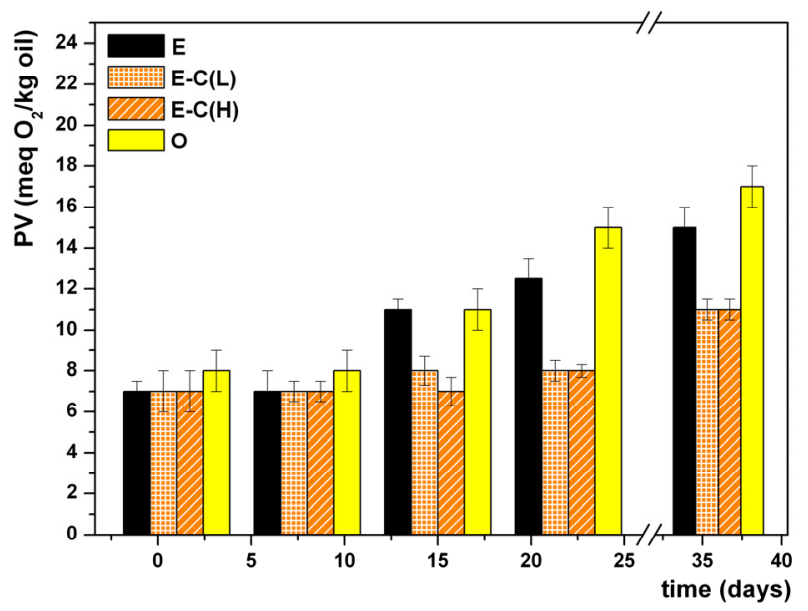

Figure 2. $\mathrm{PV}$ as a function of time in: $\mathrm{E}, \mathrm{w} / \mathrm{o}$ emulsion; E-C(L) w/o emulsion enriched with low concentration of vitamin $\mathrm{C} ; \mathrm{E}-\mathrm{C}(\mathrm{H})$ w/o emulsion enriched with high concentration of vitamin $\mathrm{C} ; \mathrm{O}$, oil (bars represent standard deviation of mean values).

The presented data showed that the presence of ascorbic acid determines the slowdown of the oil oxidation. In fact, the presence of vitamin C limited the PV variations compared to the olive oil and to w/o emulsions without vitamin fortification. On the other hand, the use of low and high concentrations of ascorbic acid did not differ significantly and controlled the oxidation to the same extent.

The antioxidant activity of ascorbic acid molecules $\left(\mathrm{AscH}^{-}\right)$depends upon their ability to scavenge peroxyl radicals according to the reaction [42]:

$$
\mathrm{ROO}^{\bullet}+\mathrm{AscH}^{-} \rightarrow \mathrm{ROOH}+\mathrm{Asc}^{\bullet-}
$$


or their ability to reduce hydroperoxides to more stable hydroxyl compounds that do not continue the radical chain reaction:

$$
\mathrm{Asc}^{\bullet-}+\mathrm{ROO}^{\bullet} \rightarrow \text { non radical combination products }
$$

The ascorbic acid mechanism of action toward lipid oxidation takes place at the water/oil interface. In a w/o emulsion the ascorbic acid is dissolved in the water droplets dispersed in the oil phase, thus, the effectiveness of the ascorbic acid action should depend on its concentration in order to have a sufficient local boundary concentration to carry out the antioxidant action. According to the presented results the lower amount of vitamin $C$ added was already effective for breaking the oxidation chain reaction.

The PV evolution in the presence of vitamin E is reported in Figure 3. The antioxidant activity of vitamin $\mathrm{E}(\mathrm{TocOH})$ can be schematized as follows:

$$
\mathrm{ROO}^{\bullet}+\mathrm{TocOH} \rightarrow \mathrm{ROOH}+\mathrm{TocO}^{\bullet}
$$

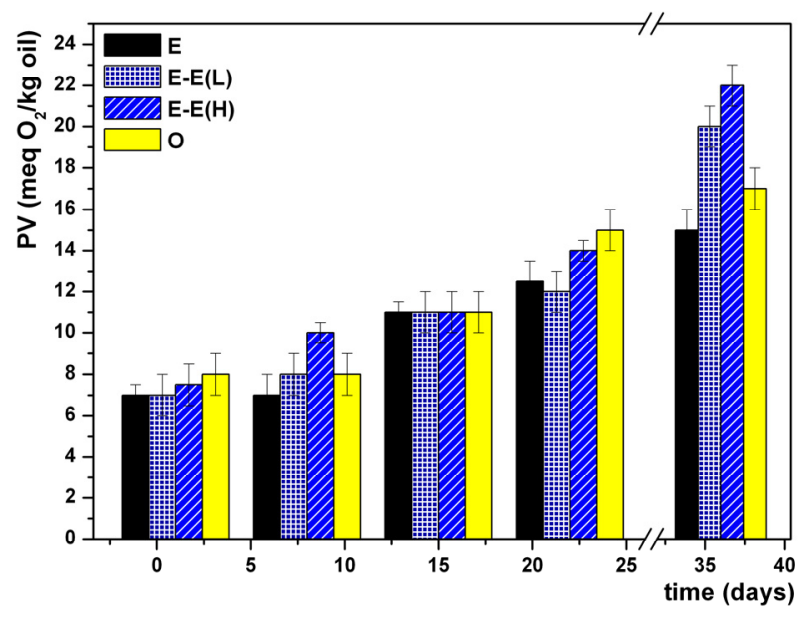

Figure 3. PV as a function of time in: $E, w / o$ emulsion; $E-E(L) w / o$ emulsion enriched with low concentration of vitamin $\mathrm{E}$; $\mathrm{E}-\mathrm{E}(\mathrm{H}) \mathrm{w} / \mathrm{o}$ emulsion enriched with high concentration of vitamin $\mathrm{E} ; \mathrm{O}$, oil (bars represent standard deviation of mean values).

The vitamin E radical formed is stable and is removed from the chain reaction by reacting with another peroxyl radical to form an inactive, non-radical product [43].

On the other hand, Figure 3 highlights that the vitamin enrichment did not break the oxidation chain during storage. The PV values, indeed, were higher in $\mathrm{E}-\mathrm{E}(\mathrm{L})$ and $\mathrm{E}-\mathrm{E}(\mathrm{H})$ than in emulsions without the antioxidant or in oil.

As can be inferred from Figure 3, the oil enrichment with $\alpha$-tocopherol worsened the oil oxidation susceptibility. Vitamin E, indeed, may work as an antioxidant or a pro-oxidant agent [44]. This dualistic nature is explained by the following mechanism:

$$
\begin{gathered}
\mathrm{TocOH} \stackrel{\text { oxidation }}{\rightarrow} \mathrm{TocO} \\
\mathrm{TocO}^{\bullet}+\mathrm{RH} \rightarrow \mathrm{TocOH}+\mathrm{R}^{\bullet}
\end{gathered}
$$

the radical species $R^{\bullet}$ produced in (9) will continue the oxidation reaction as from Equations (2) to (5). Upon oxidative stress, if present at high levels, $\alpha$-tocopherol generates increased levels of $\alpha$-tocopherol radicals that can initiate the processes of lipid oxidation by themselves. 
Figure 4 shows the comparison of the consequence of the vitamin $\mathrm{E}$ enrichment in oil (O-E(L) and $\mathrm{O}-\mathrm{E}(\mathrm{H}))$ and w/o emulsions (E-E(L) and E-E(H)). It seemed that after about two weeks the $\alpha$-tocopherol addition promoted the progress of the oxidation more in the emulsions than in the plain oil.

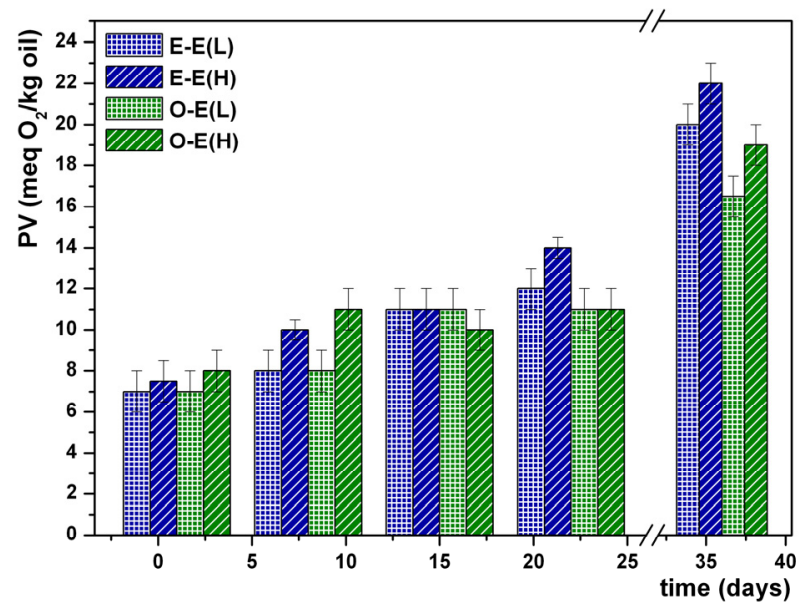

Figure 4. $\mathrm{PV}$ as a function of time in: $\mathrm{E}-\mathrm{E}(\mathrm{L}) \mathrm{w} / \mathrm{o}$ emulsion enriched with low concentration of vitamin $\mathrm{E} ; \mathrm{E}-\mathrm{E}(\mathrm{H}) \mathrm{w} / \mathrm{o}$ emulsion enriched with high concentration of vitamin $\mathrm{E}$; $\mathrm{O}-\mathrm{E}(\mathrm{L})$ oil enriched with low concentration of vitamin $\mathrm{E}$; $\mathrm{O}-\mathrm{E}(\mathrm{H})$ oil enriched with high concentration of vitamin $\mathrm{E}$ (bars represent standard deviation of mean values).

The last cases considered regarded the effect of the addition of both the vitamins in the same water-in-oil emulsions at low and high concentrations, $\mathrm{E}-\mathrm{C} / \mathrm{E}(\mathrm{L})$ and $\mathrm{E}-\mathrm{C} / \mathrm{E}(\mathrm{H})$, respectively. The PV as a function of time is reported in Figure 5 as a comparison among $E-C / E(L)$ and $E-C / E(H)$ with the non-fortified emulsion and the oil. The occurrence of a synergistic effect between the two vitamins is evident from figure since the progress of the oxidation is strongly inhibited in particular in w/o emulsions containing high amounts of vitamins $(\mathrm{E}-\mathrm{C} / \mathrm{E}(\mathrm{H}))$.

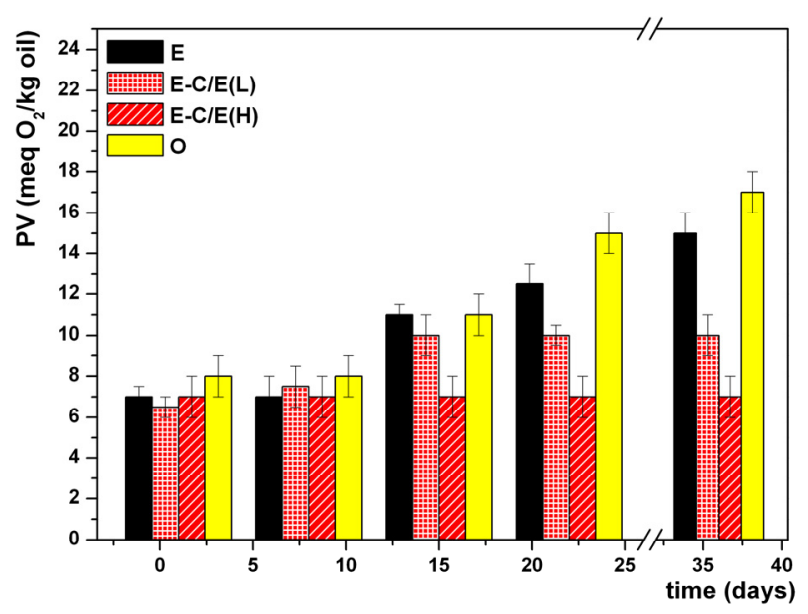

Figure 5. $\mathrm{PV}$ as a function of time in: $\mathrm{E}, \mathrm{w} / \mathrm{o}$ emulsion; $\mathrm{E}-\mathrm{C} / \mathrm{E}(\mathrm{L}) \mathrm{w} / \mathrm{o}$ emulsion enriched with low concentration of vitamin $\mathrm{C}$ and vitamin $\mathrm{E} ; \mathrm{E}-\mathrm{C} / \mathrm{E}(\mathrm{H}) \mathrm{w} / \mathrm{o}$ emulsion enriched with high concentration of vitamin $\mathrm{C}$ and vitamin $\mathrm{E}$; $\mathrm{O}$, oil (bars represent standard deviation of mean values).

The presence of both the antioxidant inhibited the pro-oxidant action of vitamin E radicals since ascorbic acid reduce back the radical to vitamin E according to the following mechanism [44]:

$$
\mathrm{TocO}^{\bullet}+\mathrm{AscH}^{-} \rightarrow \mathrm{TocOH}+\mathrm{Asc}^{\bullet-}
$$


This $\alpha$-tocopherol regeneration mechanism makes the use of high concentrations of vitamin E less effective than low concentrations in association with co-antioxidants. This justification explains that foods containing small levels of vitamin E, but also co-antioxidants provide greater health benefits than vitamin E supplements.

To reinforce this conclusion, Figure 6 shows the relative values of PV as a function of time, calculated as the ratio of the PV measured at different times to the initial value $\left(\mathrm{PV}_{0}\right)$. Panel $\mathrm{A}$ of Figure 6 shows the variation relative to w/o emulsion fortified with ascorbic acid, Panel B presents the data relative to w/o emulsions fortified with vitamin $\mathrm{E}$ and Panel $\mathrm{C}$ is relative to emulsion enriched with both the antioxidants.

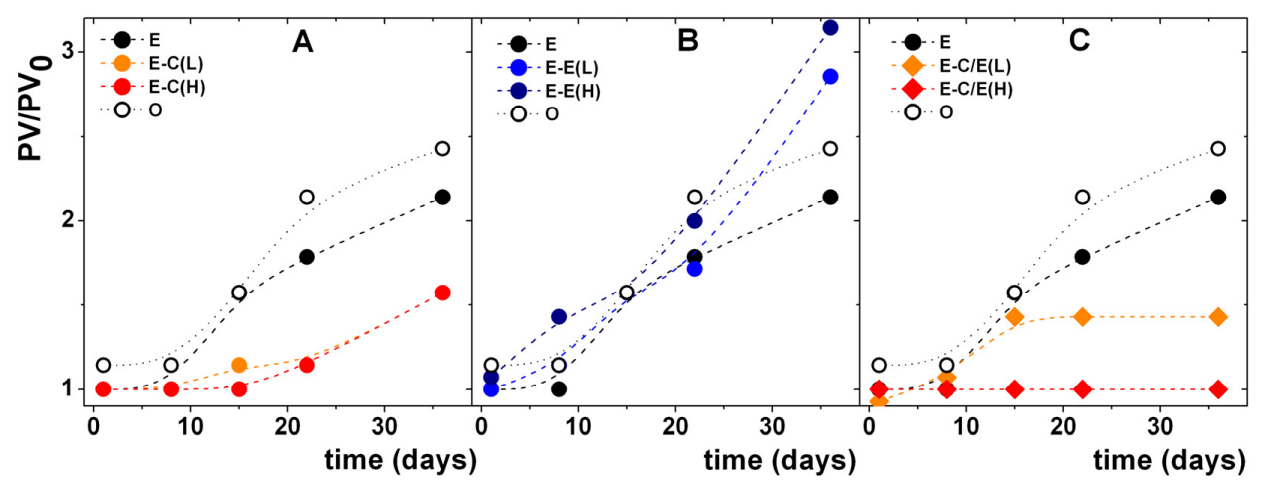

Figure 6. Relative PV variations for (A) vitamin C enriched emulsions compared with $\mathrm{E}$ and $\mathrm{O}$; (B) vitamin E enriched emulsions compared with $\mathrm{E}$ and $\mathrm{O}$; (C) vitamin $\mathrm{C}$ and vitamin $\mathrm{E}$ enriched emulsions compared with $\mathrm{E}$ and $\mathrm{O}$.

The principal evidence that emerged from figure is that the synergistic effect played by the presence of both the antioxidants is not the simple mathematical sum of their effect, but the vitamin E changed completely its activity moving from a pro-oxidant to a valuable antioxidant agent and that the use of high amounts of antioxidants protected the oil from the oxidation maintaining the PV value unchanged for the time considered.

\section{Conclusions}

In the present investigation, a study on the emulsion enrichment with vitamins was proposed. First, a suitable emulsion composition was selected choosing among different types and concentration of emulsifiers. Among the formulations considered the most stable was the one containing Span $80(1 \%)$ and water $(1 \%)$, which was selected for further enrichment with vitamins. Vitamin C and E were added separately or together to water-in-oil emulsions and their ability to influence the oil oxidation was evaluated. It resulted that vitamin $C$ was able to slow down the oxidation reaction, while vitamin $\mathrm{E}$ had a pro-oxidant effect due to its high concentration. When loaded together, vitamin $\mathrm{E}$ and vitamin $\mathrm{C}$ acted synergistically thus ensuring the vitamin $\mathrm{E}$ regeneration, the oxidation chain breaking and a longer emulsion shelf life. This last strategy allows the use of w/o emulsions as vitamin E fortified preparation.

Author Contributions: Data curation F.C.; investigation, G.C., C.C. and F.C.; methodology, G.C., F.C., F.L., E.M.; project administration, F.L.; writing - original draft, F.C. and F.L. All authors have read and agreed to the published version of the manuscript.

Funding: This research received no external funding.

Acknowledgments: This study was partially supported by CSGI (Center for Colloid and Surface Science-Florence-ITALY).

Conflicts of Interest: The authors declare no conflicts of interest. 


\section{References}

1. FAO. The State of Food and Agricolture. FAO Agriculture Series; Food and Agriculture Organization: Rome, Italy, 1996; Volume 29.

2. Doley, J. Chapter 14-Vitamins and Minerals in Older Adults: Causes, Diagnosis, and Treatment of Deficiency. In Nutrition and Functional Foods for Healthy Aging; Watson, R.R., Ed.; Academic Press: London, UK, 2017; pp. 125-137.

3. Atkinson, J.; Epand, R.F.; Epand, R.M. Tocopherols and tocotrienols in membranes: A critical review. Free Radic. Biol. Med. 2008, 44, 739-764. [CrossRef] [PubMed]

4. Li, Y.-J.; Luo, S.-C.; Lee, Y.-J.; Lin, F.-J.; Cheng, C.-C.; Wein, Y.-S.; Kuo, Y.-H.; Huang, C.-J. Isolation and Identification of $\alpha$-CEHC Sulfate in Rat Urine and an Improved Method for the Determination of Conjugated $\alpha$-CEHC. J. Agric. Food Chem. 2008, 56, 11105-11113. [CrossRef] [PubMed]

5. Lešková, E.; Kubíková, J.; Kováčiková, E.; Košická, M.; Porubská, J.; Holčíková, K. Vitamin losses: Retention during heat treatment and continual changes expressed by mathematical models. J. Food Compos. Anal. 2006, 19, 252-276. [CrossRef]

6. Niki, E.; Kawarami, A.; Yammamoto, Y.; Kamiya, Y. Oxidation of lipids VIII. Synergistic inhibition of oxidation of phosphatidylcholine liposomes in acqueous dispersions by Vitamin E and Vitamin C. Bull. Chem. Soc. Jpn. 1985, 58, 1971-1975. [CrossRef]

7. Cinelli, G.; Cuomo, F.; Hochkoeppler, A.; Ceglie, A.; Lopez, F. Use of Rhodotorula minuta live cells hosted in water-in-oil macroemulsion for biotrasformation reaction. Biotechnol. Prog. 2006, 22, 689-695. [CrossRef]

8. Perugini, L.; Cinelli, G.; Cofelice, M.; Ceglie, A.; Lopez, F.; Cuomo, F. Effect of the coexistence of sodium caseinate and Tween 20 as stabilizers of food emulsions at acidic pH. Colloids Surf. B 2018, 168, 163-168. [CrossRef]

9. Cuomo, F.; Perugini, L.; Marconi, E.; Messia, M.C.; Lopez, F. Enhanced Curcumin Bioavailability through Nonionic Surfactant/Caseinate Mixed Nanoemulsions. J. Food Sci. 2019, 84, 2584-2591. [CrossRef]

10. Dickinson, E. Double Emulsions Stabilized by Food Biopolymers. Food Biophys. 2011, 6, 1-11. [CrossRef]

11. Galus, S.; Kadzińska, J. Food applications of emulsion-based edible films and coatings. Trends Food Sci. Technol. 2015, 45, 273-283. [CrossRef]

12. Robins, M.M.; Watson, A.D.; Wilde, P.J. Emulsions - Creaming and rheology. Curr. Opin. Colloid Interface Sci. 2002, 7, 419-425. [CrossRef]

13. Sarkar, A.; Zhang, S.; Holmes, M.; Ettelaie, R. Colloidal aspects of digestion of Pickering emulsions: Experiments and theoretical models of lipid digestion kinetics. Adv. Colloid Interface Sci. 2019, 263, 195-211. [CrossRef] [PubMed]

14. Charoen, R.; Jangchud, A.; Jangchud, K.; Harnsilawat, T.; Decker, E.A.; McClements, D.J. Influence of interfacial composition on oxidative stability of oil-in-water emulsions stabilized by biopolymer emulsifiers. Food Chem. 2012, 131, 1340-1346. [CrossRef]

15. McClements, D.J. Food Emulsions: Principles, Practices, and Techniques, 2nd ed.; CRC Press: Boca Raton, FL, USA, 2004; pp. 1-609.

16. Cinelli, G.; Cuomo, F.; Ambrosone, L.; Venditti, F.; Lopez, F. Determination of bisphenol A in red wine using a double vortex-ultrasound-assisted microextraction assay: Role of the interfacial properties. Biotechnol. Prog. 2019, 35, e2780. [CrossRef] [PubMed]

17. Pekkarinen, S.S.; Stöckmann, H.; Schwarz, K.; Heinonen, I.M.; Hopia, A.I. Antioxidant activity and partitioning of phenolic acids in bulk and emulsified methyl linoleate. J. Agric. Food Chem. 1999, 47, 3036-3043. [CrossRef]

18. Xenakis, A.; Papadimitriou, V.; Sotiroudis, T.G. Colloidal structures in natural oils. Curr. Opin. Colloid Interface Sci. 2010, 15, 55-60. [CrossRef]

19. Kargar, M.; Spyropoulos, F.; Norton, I. The effect of interfacial microstructure on the lipid oxidation stability of oil-in-water emulsions. J. Colloid Interface Sci. 2011, 357, 527-533. [CrossRef]

20. Ambrosone, L.; Cinelli, G.; Mosca, M.; Ceglie, A. Susceptibility of water-emulsified extra virgin olive oils to oxidation. J. Am. Oil Chem. Soc. 2006, 83, 165-170. [CrossRef]

21. Schwarz, K.; Huang, S.W.; German, J.B.; Tiersch, B.; Hartmann, J.; Frankel, E.N. Activities of antioxidants are affected by colloidal properties of oil-in-water and water-in-oil emulsions and bulk oils. J. Agric. Food Chem. 2000, 48, 4874-4882. [CrossRef] 
22. Berton-Carabin, C.C.; Ropers, M.H.; Genot, C. Lipid Oxidation in Oil-in-Water Emulsions: Involvement of the Interfacial Layer. Compr. Rev. Food Sci. Food Saf. 2014, 13, 945-977. [CrossRef]

23. Cinelli, G.; Sbrocchi, G.; Iacovino, S.; Ambrosone, L.; Ceglie, A.; Lopez, F.; Cuomo, F. Red Wine-Enriched Olive Oil Emulsions: Role of Wine Polyphenols in the Oxidative Stability. Colloids Interfaces 2019, 3, 59. [CrossRef]

24. Waraho, T.; McClements, D.J.; Decker, E.A. Mechanisms of lipid oxidation in food dispersions. Trends Food Sci. Technol. 2011, 22, 3-13.

25. Mosca, M.; Cuomo, F.; Lopez, F.; Ceglie, A. Role of emulsifier layer, antioxidants and radical initiators in the oxidation of olive oil-in-water emulsions. Food Res. Int. 2013, 50, 377-383. [CrossRef]

26. Yi, J.; Zhu, Z.; McClements, D.J.; Decker, E.A. Influence of aqueous phase emulsifiers on lipid oxidation in water-in-walnut oil emulsions. J. Agric. Food Chem. 2014, 62, 2104-2111. [CrossRef] [PubMed]

27. Tikekar, R.V.; Nitin, N. Distribution of encapsulated materials in colloidal particles and its impact on oxidative stability of encapsulated materials. Langmuir 2012, 28, 9233-9243. [CrossRef] [PubMed]

28. Frei, B. Reactive oxygen species and antioxidant vitamins: Mechanisms of action. Am. J. Med. 1994, 97, S5-S13. [CrossRef]

29. Liu, D.; Shi, J.; Colina Ibarra, A.; Kakuda, Y.; Jun Xue, S. The scavenging capacity and synergistic effects of lycopene, vitamin E, vitamin $\mathrm{C}$, and $\beta$-carotene mixtures on the DPPH free radical. LWT-Food Sci. Technol. 2008, 41, 1344-1349. [CrossRef]

30. Dai, F.; Chen, W.F.; Zhou, B. Antioxidant synergism of green tea polyphenols with $\alpha$-tocopherol and l-ascorbic acid in SDS micelles. Biochimie 2008, 90, 1499-1505. [CrossRef]

31. Coates Barclay, L.R.; Locke, S.J.; Macneil, J.M. Autoxidation in micelles. Synergism of vitamin C with lipid-soluble vitamin E and water-soluble Trolox. Can. J. Chem. 1985, 63, 366-374. [CrossRef]

32. Gitto, E.; Tan, D.-X.; Reiter, R.J.; Karbownik, M.; Manchester, L.C.; Cuzzocrea, S.; Fulia, F.; Barberi, I. Individual and synergistic antioxidative actions of melatonin: Studies with vitamin $\mathrm{E}$, vitamin $\mathrm{C}$, glutathione and desferrrioxamine (desferoxamine) in rat liver homogenates. J. Pharm. Pharmacol. 2001, 53, 1393-1401. [CrossRef]

33. Mosca, M.; Ceglie, A.; Ambrosone, L. Biocompatible water-in-oil emulsion as a model to study ascorbic acid effect on lipid oxidation. J. Phys. Chem. B 2008, 112, 4635-4641. [CrossRef]

34. Commission Regulation (EEC) No. 2568/91 of 11 July 1991 on the characteristics of olive oil and olive-residue oil and on the relevant methods of analysis Official Journal L 248, 5 September 1991. Off. J. L 1991, 248, 1-83.

35. Csáki, K.F. Synthetic surfactant food additives can cause intestinal barrier dysfunction. Med. Hypotheses 2011, 76, 676-681. [PubMed]

36. Moonen, H.; Bas, H. Mono-and diglycerides. Emuls. Food Technol. 2004, 40-58.

37. Kruglyakov, P.M.; Mal'kov, V.D.; Sedova, T.P. The effect of fatty alcohols and valeric acid on the regions of existence of a three-phase system containing water, oil, and surfactant. Colloid J. 2002, 64, 719-724. [CrossRef]

38. Jain, G.; Khar, R.K.; Ahmad, F.J. Theory and Practice of Physical Pharmacy-E-Book; Elsevier Health Sciences: Amsterdam, The Netherlands, 2013.

39. Song, M.-G.; Cho, S.-H.; Kim, J.-Y.; Kim, J.-D. Novel evaluation method for the water-in-oil (W/O) emulsion stability by turbidity ratio measurements. Korean J. Chem. Eng. 2002, 19, 425-430. [CrossRef]

40. Mosca, M.; Ceglie, A.; Ambrosone, L. Antioxidant dispersions in emulsified olive oils. Food Res. Int. 2008, 41, 201-207.

41. Barakat, M.Z.; Shehab, S.K.; Darwish, N.; El-Zoheiry, E. A new titrimetric method for the determination of vitamin C. Anal. Biochem. 1973, 53, 245-251. [CrossRef]

42. Pokorný, J.; Yanishlieva, N.; Gordon, M. Antioxidants in Food: Practical Applications; Elsevier: Amsterdam, The Netherlands, 2001.

43. Yamauchi, R. Vitamin E: Mechanism of its antioxidant activity. Food Sci. Technol. Int. Tokyo 1997, 3, 301-309. [CrossRef]

44. Rietjens, I.M.C.M.; Boersma, M.G.; Haan, L.D.; Spenkelink, B.; Awad, H.M.; Cnubben, N.H.P.; Van Zanden, J.J.; Woude, H.V.D.; Alink, G.M.; Koeman, J.H. The pro-oxidant chemistry of the natural antioxidants vitamin C, vitamin E, carotenoids and flavonoids. Environ. Toxicol. Pharmacol. 2002, 11, 321-333. [CrossRef] 